\title{
Implication of calibration period on modelling climate change impact on future runoff
}

\author{
F. H. S. Chiew, H. Zheng, and J. Vaze \\ CSIRO Land and Water Flagship, G.P.O. Box 1666, Canberra, ACT 2601, Australia \\ Correspondence to: F. H. S. Chiew (francis.chiew@csiro.au)
}

Received: 11 March 2015 - Accepted: 11 March 2015 - Published: 12 June 2015

\begin{abstract}
This paper explores the consideration and implication of calibration period on the modelled climate change impact on future runoff. The results show that modelled runoff and hydrologic responses can be influenced by the choice of historical data period used to calibrate and develop the hydrological model. Modelling approaches that do not take this into account may therefore underestimate the range and uncertainty in future runoff projections. Nevertheless, the uncertainty associated with the choice of hydrological models and consideration of calibration dataset for modelling climate change impact on runoff is likely to be small compared to the uncertainty in the future rainfall projections.
\end{abstract}

\section{Introduction}

Hydrologists have excelled in developing models for numerous applications, through analysing and interpreting climate and hydrologic data to understand hydrologic processes, conceptualising the processes in hydrological models, and calibrating and testing models against observations. These models are particularly good in predicting streamflow response to changes in the climate inputs and catchment characteristics. In fact, practically all climate change impact on runoff studies use future climate series informed by projections from climate models to drive a hydrological model developed and calibrated against past hydroclimate data (e.g. Chiew et al., 2009). However, interpreting results from these simulations will become more challenging as we extrapolate the hydrological models to predict further into the future where hydrological fluxes and stores will be influenced not only by the changed climate input data, but increasingly by higher temperature and changed ecohydrological processes under higher $\mathrm{CO}_{2}$ not seen in the past (Chiew et al., 2014).

Most climate change impact studies use hydrological models developed and calibrated against the entire length of available observed historical hydroclimate data. This is sensible because a long historical dataset can better encapsulate the large range of hydroclimate conditions. Nevertheless, simulations using parameter values from model calibration against data from different subset of historical periods often lead to different modelling results (Vaze et al., 2010; Coron et al., 2012). This raises the question of whether future hydrological predictions should be modelled using parameter values from calibration against a historical period that is similar to the future climate projections (e.g. similar average rainfall) instead of parameter values from calibration against the entire historical dataset.

This paper explores the consideration of calibration period (entire historical data versus period that best matches future rainfall projections) on the modelled climate change impact on future runoff. Specifically, the paper investigates the uncertainty introduced by the choice of calibration period (and the choice of hydrological models) relative to uncertainties in the future climate projections. The modelling experiments are carried out by applying two hydrological models with future climate projections from 14 global climate models on two catchments in Australia.

\section{Data}

Figure 1 shows the locations and the annual rainfall and runoff time series of the two catchments used in this study. The daily rainfall and potential evapotranspiration (PET) data come from the SILO Data Drill $0.05^{\circ}$ gridded climate data for Australia (http://www.longpaddock.qld.gov.au/silo/; Jeffrey et al., 2001). The daily streamflow for the two unreg- 

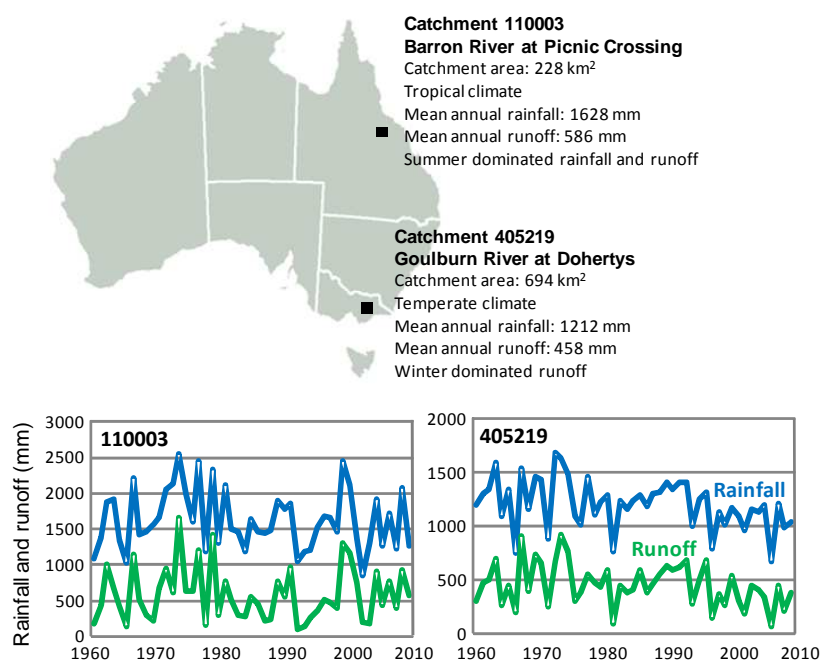

Figure 1. Locations of the two catchments used in the study and their annual rainfall and runoff time series.

ulated and largely unimpaired catchments come from the respective state water agencies. Daily rainfall, PET and streamflow data from 1961 to 2009 are used for this study.

Simulations for RCP4.5 from 14 global climate models (GCMs) (for which archives of rainfall and PET are readily available) from the latest CMIP5 multi-model ensemble dataset (http://cmip-pcmdi.llnl.gov/cmip5/; Taylor et al., 2012) are used to inform the range of plausible future climate projections. The RCP4.5 is a representative concentration pathway with a radiative forcing of $4.5 \mathrm{~W} \mathrm{~m}^{-2}$ in 2100 relative to pre-industrial value. The GCM simulations for 2046-2065 relative to 1986-2005 (increase in global temperature of $1-2{ }^{\circ} \mathrm{C}$ ) are used to inform the range of projected change in mean annual rainfall and PET.

\section{Modelling experiments}

In the modelling experiments, the "historical runoff" is modelled using the 1961-2009 daily rainfall and PET data. The "future runoff" is modelled using the 1961-2009 daily rainfall and PET series scaled by a single factor informed by the relative difference between the future and historical mean annual rainfall and PET simulated by each of the 14 GCMs. This simplistic 'delta scaling approach' therefore considers only changes in the annual averages with no change in the sequence, distribution or seasonality in the future climate inputs.

Two simple and commonly used daily rainfall-runoff models are used in this study, GR4J (Perrin et al., 2003) and SIMHYD (Chiew et al., 2002). The modelling is carried out for two calibration considerations, (i) modelling with parameter values from model calibration against the entire 19612009 data (Method A), and (ii) modelling with parameter values from model calibration against a 15-year historical period with mean annual rainfall that is most similar to the future rainfall projections (up to 14 different calibration periods depending on future projections from the 14 GCMs) (Method B). In the model calibration, the parameter values are optimised to produce the best least-squares fit between the daily modelled and observed streamflows by maximising the Nash-Sutcliffe efficiency (Nash and Sutcliffe, 1970).

\section{Results}

The modelling results for Catchments 110003 and 405219 are summarised in Figs. 2 and 3 respectively. The left hand plots show results from the GR4J rainfall-runoff model and the right hand plots show results from the SIMHYD rainfallrunoff model. The top row shows the percentage change in future mean annual rainfall from the $14 \mathrm{GCMs}$. The middle row shows the 1961-2009 mean annual runoff modelled using optimised parameter values from model calibration against the entire 1961-2009 data (Method A) (blue) and modelled using optimised parameter values from model calibration against a 15 -year historical period with mean annual rainfall most similar to the future rainfall projection (Method B) (red). The bottom row shows the change in modelled future mean annual runoff (using 1961-2009 climate inputs scaled by change informed by the GCMs) relative to modelled historical mean annual runoff (using 19612009 climate inputs) from Method A and Method B. The 14 columns/bars or pair of columns in the plots show results informed by the relative rainfall change from the $14 \mathrm{GCMs}$, and are consistently aligned in all the plots.

Both catchments exhibit high inter-annual and interdecadal variability in rainfall which is amplified in the runoff variability (Fig. 1). The range in the future rainfall projection is large, and the direction of rainfall change in Catchment 110003 is uncertain (10th to 90th percentile range of -13 to $+12 \%$ across the 14 GCMs) whilst practically all the GCMs project a rainfall decrease in Catchment 405219 (range of -13 to $+2 \%$ ) (top row in Figs. 2 and 3). It is also interesting to note that far south-eastern Australia experienced an unprecedented 1997-2009 Millennium Drought that has been partly attributed to climate change (Catchment 405219 in Fig. 1) (Post et al., 2014). The change in rainfall is amplified as about twice as much percentage change in the modelled runoff (bottom row in Figs. 2 and 3) (see also Chiew, 2006). The future runoffs modelled by the two hydrological models are relatively similar compared to the large range in the future rainfall projections.

In Catchment 405219, using parameter values from calibration against a dry 15-year period (Method B) resulted in higher modelled runoff compared to using parameter values from calibration against the entire 1961-2009 data (Method A) (middle row in Fig. 3 for the four driest future rainfall projections). This translated to higher modelled future runoff in Method B and therefore smaller projected de- 
- Each column or pair of columns in the plots show results informed by the relative rainfall change from the $14 \mathrm{GCMs}$, consistently aligned in all the plots.

- Blue columns show results modelled using parameter values from model calibration against the entire 1961-2009 data.

- Red columns show results modelled using parameter values from model calibration against a 15year historical period with mean annual rainfall most similar to the future rainfall projections.

GR4
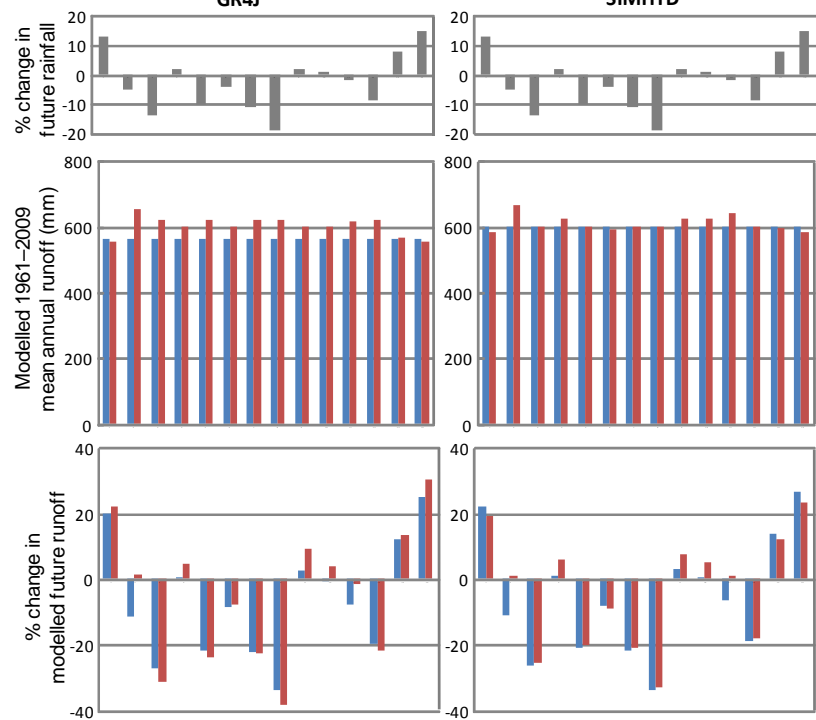

Figure 2. Modelling results for Catchment 110003.

clines (bottom row in Fig. 3 for the four driest future projections) and a slightly smaller range in future runoff projections from Method B ( -25 to $+3 \%$ for GR4J and -24 to $+6 \%$ for SIMHYD) compared to Method A ( -30 to $0 \%$ for GR4J and -25 to $+6 \%$ for SIMHYD).

In Catchment 110003, for the wet future projections, both Methods A and B give similar results. For the dry projections, the SIMHYD modelling results for Methods A and B are also similar. For the dry projections, the GR4J modelled runoff is higher in Method B compared to Method A (GR4J modelling in second row of Fig. 2). However, the modelled future runoff in the dry projections is lower in Method B (GR4J modelling in third row of Fig. 3) resulting in a bigger range in the future runoff projections in Method B $(-29$ to $+20 \%)$ compared to Method A ( -26 to $+18 \%)$.

\section{Discussion}

There is large uncertainty in future rainfall projections and this is amplified in the future runoff projections. Many studies have shown that the uncertainty in the future rainfall projections (from GCMs and downscaling models) is much larger than the uncertainty in different hydrological model responses to changes in input climate data (e.g. Teng et al., 2012).

Although the modelled runoff with different parameter values optimised using different calibration datasets may differ significantly, there has been little to no studies on the implications of choice of calibration period on the modelling
- Each column or pair of columns in the plots show results informed by the relative rainfall change from the $14 \mathrm{GCMs}$, consistently aligned in all the plots.

Blue columns show results modelled using parameter values from model calibration against the entire 1961-2009 data.

- Redcolumns how resuls modeledusing arametervalues from modelcalbration aganst a 15Red columns show results modelled using parameter values from model calibration against a $15-$
year historical period with mean annual rainfall most similar to the future rainfall projections.
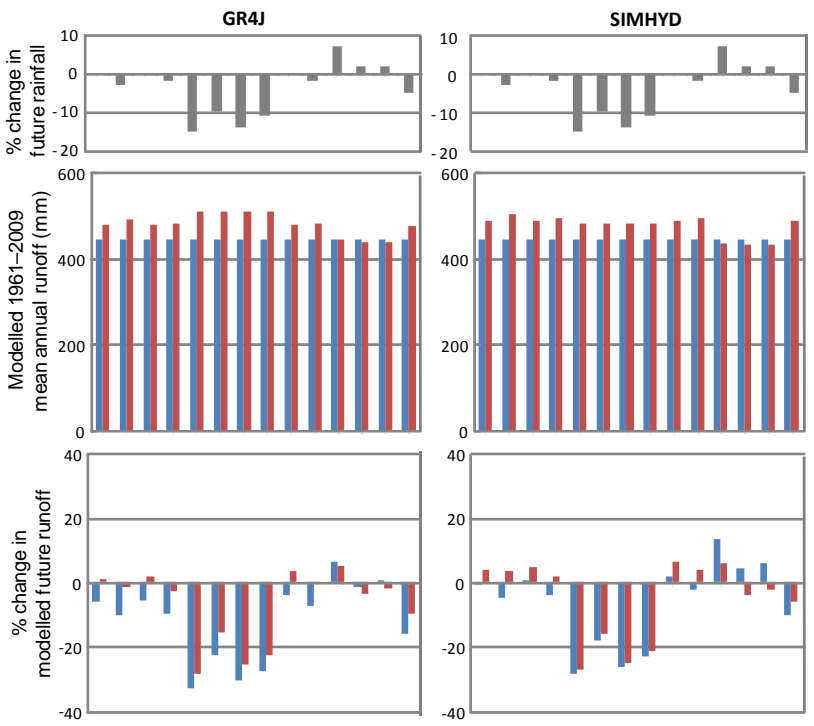

Figure 3. Modelling results for Catchment 405219.

of climate change impact on future runoff. The least-squares optimisation of parameter values generally results in underestimation of high flows and overestimation of low flows. It follows then that modelling with parameter values from calibration against a dry period may tend to simulate lower flows and vice versa. Therefore, for a future dry projection, using parameter values from calibration against a dry period similar to the future dry projection may result in a greater decline in the modelled future runoff (Method B) compared to using parameter values from calibration against all available data (Method A). Likewise, for a future wet projection, using parameter values from calibration against a wet period similar to the future wet projection may result in a greater increase in the modelled future runoff. The range in the future runoff projections may therefore be larger when modelled using parameter values from calibration against a similar dry/wet period as the future projections (Method B) compared to modelling with parameter values from calibration against the entire historical dataset (Method A).

However, the modelling results here show that this is not necessarily the case. Several studies have also shown that parameter values obtained from calibration against a dry (or wet) period does not necessarily simulate lower (or higher) runoff (Vaze et al., 2010; Coron et al., 2012). These studies observed runoff responses in both directions and attributed the different responses to the different model conceptualisations and how the model parameters and storages respond to dry and wet periods. In line with the reasoning in the above paragraph then, where modelling with parameter values from calibration over a dry period simulates a bigger decline in fu- 
ture runoff and vice versa, adopting a calibration period similar to the future rainfall period will increase the range and uncertainty in the future runoff projections compared to the traditional method adopting parameter values from calibration against the entire dataset for all simulations. Conversely, where modelling with parameter values from calibration over a dry period simulates a smaller decline in future runoff and vice versa, adopting a calibration period similar to the future rainfall period will decrease the range in the future runoff projections.

Given the potential impact of the calibration period, there are good reasons to consider using parameter values obtained from model calibration against a dry/wet period(s) similar to the future rainfall projection(s) to model the future runoff(s). This is particularly so where a single hydrological model has been chosen or developed specifically for a particular region and/or study objective or where a model can be developed or conceptualised differently to better represent different hydroclimate conditions. Nevertheless, the results from the limited modelling experiments here (e.g. only two catchments and two hydrological models, with a very simplistic consideration of changed future climate inputs) show that the difference in runoff responses from different model calibration considerations is likely to be small relative to the uncertainty/range in the future rainfall projections. This is particularly so when ensembles from multiple hydrological models are used as the different models can show biased responses in different directions.

\section{Conclusions}

The modelled runoff and hydrologic responses can be influenced by the choice of historical data period used to calibrate and develop the hydrological model. As it is difficult to develop a perfect hydrological model that works under all conditions (particularly when extrapolating to a future under warmer and higher $\mathrm{CO}_{2}$ conditions not seen in the past), there are good reasons to use hydrologic conceptualisations and parameter values optimised over a historical data period that is similar to the future climate projections for climate change impact modelling. Nevertheless, the uncertainty associated with the choice of hydrological models and consideration of calibration dataset for modelling climate change impact on runoff is likely to be small compared to the uncertainty in the future rainfall projections.

\section{References}

Chiew, F. H. S.: Estimation of rainfall elasticity of streamflow in Australia, Hydrol. Sci. J., 51, 613-625, doi:10.1623/hysj.51.4.613, 2006.

Chiew, F. H. S., Peel, M. C., and Western, A. W.: Application and testing of the simple rainfall-runoff model SIMHYD, in: Mathematical Models of Small Watershed Hydrology and Applications, edited by: Singh, V. P. and Frevert, D. K., Water Resources Publication, Littleton, Colorado, 335-367, 2002.

Chiew, F. H. S., Teng, J., Vaze, J., Post, D. A., Perraud, J.-M., Kirono, D. G. C., and Viney, N. R.: Estimating climate change impact on runoff across south-east Australia: method, results and implications of modelling method, Water Resour. Res., 45, W10414, doi:10.1029/2008WR007338, 2009.

Chiew, F. H. S., Potter, N. J., Vaze, J., Petheram, C., Zhang, L., and Post, D. A.: Observed hydrologic non-stationarity in far south-eastern Australia: implications and future modelling predictions, Stochast. Environm. Res. Risk Assess., 28, 3-15, doi:10.1007/s00477-013-0755-5, 2014.

Coron, L., Andreassian, V., Perrin, C., Lerat, J., Vaze, J., Bourqui, M., and Hendrickx, F.: Crash testing hydrological models in contrasted climate conditions: an experiment on 216 Australian catchments, Water Resour. Res., 48, W05552, doi:10.1029/2011WR011721, 2012.

Jeffrey, S. J., Carter, J. O., Moodie, K. B., and Beswick, A. R.: Using spatial interpolation to construct a comprehensive archive of Australian climate data, Environ. Modell. Softw., 16, 309-330, 2001.

Nash, J. E. and Sutcliffe, J. V.: River flow forecasting through conceptual models, 1, A discussion of principles, J. Hydrol., 10, 282-290, 1970.

Perrin, C., Michel, C., and Andreassian, V.: Improvement of a parsimonious model for streamflow simulations, J. Hydrol., 279, 275289, 2003.

Post, D. A., Timbal, B., Chiew, F. H. S., Hendon, H. H., Nguyen, H., and Moran, R.: Decrease in southeastern Australian water availability linked to ongoing Hadley cell expansion, Earth's Future, 2, 231-238, doi:10.1002/2013EF000194, 2014.

Taylor, K. E., Stouffer, R. J., and Meehl, G. A.: An overview of CMIP5 and the experiment design, B. Am. Meteorol. Soc., 93, 485-498, doi:10.1175/BAMS-D-11-00094.1, 2012.

Teng, J., Vaze, J., Chiew, F. H. S., Wang, B., and Perraud, J.-M.: Estimating the relative uncertainties sourced from GCMs and hydrological models in modelling climate change impact on runoff, J. Hydrometeorol., 13, 122-139, doi:10.1175/JHM-D-11-058.1, 2012.

Vaze, J., Post, D. A., Chiew, F. H. S., Perraud, J.-M., Viney, N., and Teng, J.: Climate non-stationarity - validity of calibrated rainfallrunoff models for use in climate change studies, J. Hydrol., 394, 447-457, doi:10.1016/j.jhydrol.2010.09.018, 2010. 